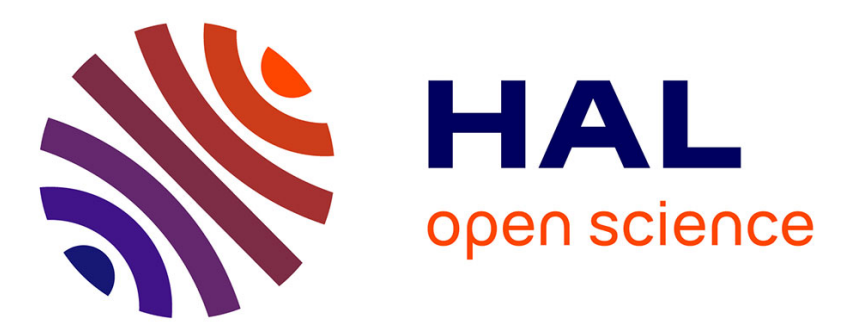

\title{
Two-dimensional versus three-dimensional constraints in hetero-epitaxy/orientation relationships
}

\author{
Paul Wynblatt, Dominique Chatain
}

\section{To cite this version:}

Paul Wynblatt, Dominique Chatain. Two-dimensional versus three-dimensional constraints in heteroepitaxy/orientation relationships. Journal of Materials Science, 2017, 52 (16), pp.9630 - 9639. $10.1007 / \mathrm{s} 10853-017-1145-\mathrm{z}$. hal-01720666

\section{HAL Id: hal-01720666 \\ https://hal.science/hal-01720666}

Submitted on 13 Apr 2018

HAL is a multi-disciplinary open access archive for the deposit and dissemination of scientific research documents, whether they are published or not. The documents may come from teaching and research institutions in France or abroad, or from public or private research centers.
L'archive ouverte pluridisciplinaire HAL, est destinée au dépôt et à la diffusion de documents scientifiques de niveau recherche, publiés ou non, émanant des établissements d'enseignement et de recherche français ou étrangers, des laboratoires publics ou privés. 
Two-dimensional versus Three-dimensional Constraints in Hetero-Epitaxy/Orientation Relationships

\author{
Paul Wynblatt ${ }^{1}$, Dominique Chatain ${ }^{2 *}$ \\ ${ }^{1}$ Department of Materials Science and Engineering, Carnegie Mellon University, Pittsburgh, \\ PA 15213, USA \\ email: pw01@andrew.cmu.edu
}

${ }^{2}$ Aix-Marseille Univ, CNRS, CINAM, 13009 Marseille, France

email: chatain@cinam.univ-mrs.fr

\begin{abstract}
Molecular Dynamics simulations have been performed to compare the orientation relationships (ORs) that develop between $\mathrm{Ag}$ films/particles equilibrated with $\mathrm{Ni}$, depending on whether the $\mathrm{Ag}$ is subjected to three-dimensional (3-D) confinement by being embedded in $\mathrm{Ni}$, or to 2-D confinement by equilibration with a Ni substrate. Previous results of both simulations and experiments have shown that $\mathrm{Ag}$ films equilibrated with planar Ni substrates display a large number of different ORs; in particular, Ag equilibrated on Ni\{100\} displays an OR of $\operatorname{Ag}\{111\}<110>/ / \mathrm{Ni}\{100\}<110>$, often referred to as an oct-cube OR. Here it is shown that a Ag particle embedded in Ni displays an OR of $\mathrm{Ag}\{111\}<110>/ / \mathrm{Ni}\{111\}<110>$, i.e. a cubeon-cube OR. It has also been shown that as the confinement of a Ag particle is gradually increased from 2-D to 3-D, by equilibrating a $\mathrm{Ag}$ particle on $\mathrm{Ni}(100)$ substrates with progressively deeper dimples, a transition in OR occurs from oct-cube to cube-on-cube. This result contradicts the conventional notion which supposes that the ORs displayed in the presence of 3-D confinement (e.g. during phase transformations) will also tend to be displayed in epitaxy on a substrate.
\end{abstract}

Keywords: orientation relationship, interface anisotropy, particle confinement, lattice mismatch, surface and interface structure 


\section{INTRODUCTION}

The orientation relationship (OR)/hetero-epitaxy that is manifested when one crystalline material grows either on or within another may depend on the dimensionality of the template on which growth takes place. For example, in phase transformations the OR that develops is one that minimizes the energy of the new phase under conditions where it is surrounded in 3-dimensions (3-D) by the parent phase, whereas in film epitaxy the OR of the film is constrained to adapt to a "flat" 2-D substrate of arbitrary but specific orientation. Thus the resultant $\mathrm{OR}$ in hetero-epitaxy of one phase on a flat surface of another phase does not necessarily need to duplicate the OR which arises in phase transformations. In this paper, we investigate the dependence of the OR on the dimensionality of the environment, by comparing the ORs that result from previous experiments [1] and computer simulations [2] of Ag (films or particles) equilibrated on flat $\mathrm{Ni}$ substrates, with simulations of a Ag particle embedded within a Ni matrix. In addition, we have performed simulations of certain configurations in which a Ag particle is partially embedded in a Ni substrate in order to investigate the transition from 2-D to 3-D behavior.

In the previous experiments [1], the ORs displayed by a Ag film/particle equilibrated on about 200 different surface orientations of a polycrystalline Ni substrate were determined. The distribution of $\mathrm{Ag}$ ORs obtained is shown schematically in the standard stereographic triangle of Fig. 1. On Ni orientations that fall within the (111)-(110)-(210) orange part of the triangle, Ag adopts a cube-on-cube OR (labeled C-C, which may be expressed as $\mathrm{Ag}\{111\}<110>/ / \mathrm{Ni}\{111\}<110>$ ), with some fraction of the Ag present in a twin-related orientation to the cube-on-cube orientation. The oct-cube OR (labeled $\mathrm{O}-\mathrm{C}$, which may be expressed as $\operatorname{Ag}\{111\}<110>/ / \mathrm{Ni}\{100\}<110>$ ) is only observed for Ag equilibrated on $\mathrm{Ni}(100)$. The dashed line connecting the (210) to (111) poles, which is the trace of the $(1 \overline{2} 1)$ plane, represents Ni substrate orientations on which Ag adopts mainly a twin OR with some cube-on-cube OR present (labeled T/C-C). Finally, for Ag on Ni orientations that fall within the (100)-(111)-(210) green portion of the triangle (and labeled S for "special") the OR of $\mathrm{Ag}$ undergoes a gradual transition from the oct-cube to the twin/cube-on-cube ORs.

In the simulations [2], which were carried out by molecular dynamics (MD) in conjunction with embedded atom method (EAM) potentials [3], the ORs that developed in $\mathrm{Ag}$ films equilibrated on 12 different $\mathrm{Ni}$ substrate orientations were found to be in excellent agreement with the experimental results. This provides some confidence that the results of computer simulation based on these EAM potentials are reliable for the $\mathrm{Ag} / \mathrm{Ni}$ system. 


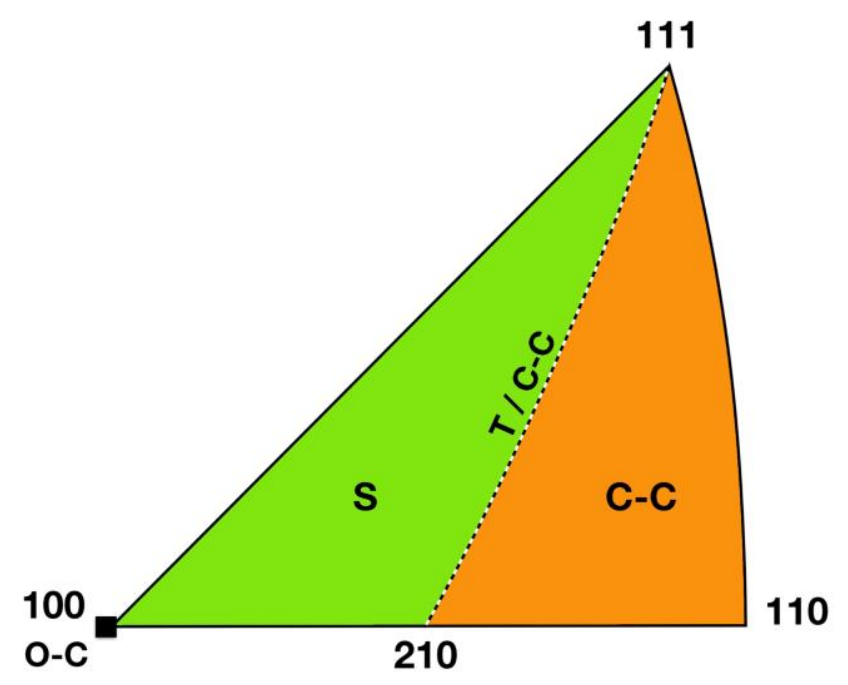

Fig. 1. Standard stereographic triangle indicating the ORs displayed by $\mathrm{Ag}$ on various $\mathrm{Ni}$ substrate orientations (2-D constraints) [1]. The region colored orange and labeled C-C represents $\mathrm{Ni}$ substrate orientations on which $\mathrm{Ag}$ adopts a cube-on-cube $\mathrm{OR}$, as well as some twin OR. Along the dashed line labeled T/C-C the Ag adopts mainly a twin OR, with some cube-on-cube OR. On the $\mathrm{Ni}(100)$ substrate (point labeled $\mathrm{O}-\mathrm{C}$ ) Ag adopts the oct-cube OR. The region colored green and labeled S (for "special") is a region where the Ag OR undergoes a gradual transition $\mathrm{O}-\mathrm{C}$ to $\mathrm{T} / \mathrm{C}-\mathrm{C}$ (color on line). See text.

As we shall see, the principal crystallographic planes of $\mathrm{Ni}$ that are stable in contact with embedded $\mathrm{Ag}$ (i.e. under 3-D constraints) are the $\mathrm{Ni}\{111\}$ and $\mathrm{Ni}\{100\}$. Since $\mathrm{Ag}\{111\}$ coexists with planar $\mathrm{Ni}\{111\}$ in the cube-on-cube $\mathrm{OR}$, whereas it coexists with planar $\mathrm{Ni}\{100\}$ in the oct-cube OR, the question of what happens when a Ag crystal is fully embedded in $\mathrm{Ni}$, where its $\{111\}$ planes cannot coexist simultaneously with both $\mathrm{Ni}\{111\}$ and $\mathrm{Ni}\{100\}$ surfaces, is worthy of investigation.

The Ni-Ag alloy system represents a convenient model system for the present study. $\mathrm{Ni}$ and $\mathrm{Ag}$ are almost insoluble in each other in the solid state, and as a result the coexisting solid equilibrium phases consist of essentially pure $\mathrm{Ni}$ and $\mathrm{Ag}$ at all temperatures. This avoids any concerns regarding the effects of compositional changes on lattice matching of the two phases.

\section{COMPUTATIONAL APPROACH}

Computational framework

Simulations were performed by molecular dynamics (MD) and/or lattice statics (LS), using the LAMMPS code [4, 5], in conjunction with EAM potentials [3]. These potentials include many body effects, and have been used extensively in previous studies of the Ag-Ni system [6-21]. MD simulations were conducted as follows. A computation cell consisting of $\mathrm{Ni}$ and $\mathrm{Ag}$ 
was heated gradually to $900 \mathrm{~K}$ over a period of $200 \mathrm{psec}$, held at $900 \mathrm{~K}$ for a period of $4 \mathrm{nsec}$ in order to approach equilibrium, and then relaxed by LS to remove thermal noise. In most cases it was found that the structure ceased to evolve significantly after equilibration times of $4 \mathrm{nsec}$ at $900 \mathrm{~K}$. If this procedure did not produce satisfactory equilibration, the above cycle was applied several more times, up to total equilibration times of 20 nsec. In a few cases, the temperature to which the computational cell was initially heated was raised to $1250 \mathrm{~K}$, before equilibrating at $900 \mathrm{~K}$.

\section{2-D constraints - films on substrates}

The results reported here on simulation of ORs of Ag films on flat substrates are taken from a previous study [2]. The initial computational cells consisted of $\mathrm{Ni}$ slabs containing between 30,000 to 50,000 atoms, with approximate dimensions of $10 \mathrm{~nm}$ in the $\mathrm{x}$ - and $\mathrm{y}$ directions, and between 4 and $6 \mathrm{~nm}$ in thickness in the z-direction. The $\mathrm{x}-\mathrm{y} \mathrm{Ni}$ surfaces were oriented in preselected (hkl) planes. The Ag films consisted of about 5,000 atoms deposited on the top Ni surface. In order to avoid configurational bias, the Ag atoms of the film were initially arranged randomly, and allowed to crystallize during the MD simulation. Periodic boundary conditions were applied in the $x$ - and $y$-directions, whereas the $z$-directions of the Ni slabs and Ag films were terminated by free surfaces.

\section{$\underline{\text { 3-D constraints - embedded particles }}$}

In order to effect complete 3-D constraints of $\mathrm{Ag}$ particles by the $\mathrm{Ni}$ matrix, configurations consisting of a Ag particle initially embedded in a spherical cavity of the matrix were employed. The Ni matrix consisted of about 100,000 atoms arranged in the form of a cube, which contained a centrally located Ag particle of about 4000 atoms. 3-D periodic boundary conditions were applied to these computations.

In the case of simulations of Ag particles embedded in a Ni matrix, it was not possible to use an initially random distribution of Ag within the Ni cavity, as the lower density of the randomly distributed Ag would have led to undesirable voids, as a result of shrinkage during MD equilibration. However, in order to avoid bias in the final OR of completely embedded $\mathrm{Ag}$, three different initial configurations were explored. These consisted of (a) an embedded $\mathrm{Ag}$ particle in an initially oct-cube OR: $\mathrm{Ag}(111)[01 \overline{1}] / / \mathrm{Ni}(100)[01 \overline{1}]$; (b) an initial OR that corresponded to neither the oct-cube nor the cube-on-cube $\mathrm{OR}$, in which the Ag particle was placed in the $\mathrm{Ni}$ matrix after rotation by $45^{\circ}$ about the $\mathrm{z}$-axis, thus giving a $\mathrm{Ag}(001)[100] / / \mathrm{Ni}(001)[110] \mathrm{OR}$; and (c) a configuration where the Ag was given a cube-oncube OR in the Ni matrix. In each case, the Ni cavity was trimmed by gradually removing $\mathrm{Ni}$ 
atoms that were closer than a prescribed distance from $\mathrm{Ag}$ atoms. Each of the resulting configurations was relaxed by lattice statics, and the minimum energy configuration was then used as the initial configuration for further computation.

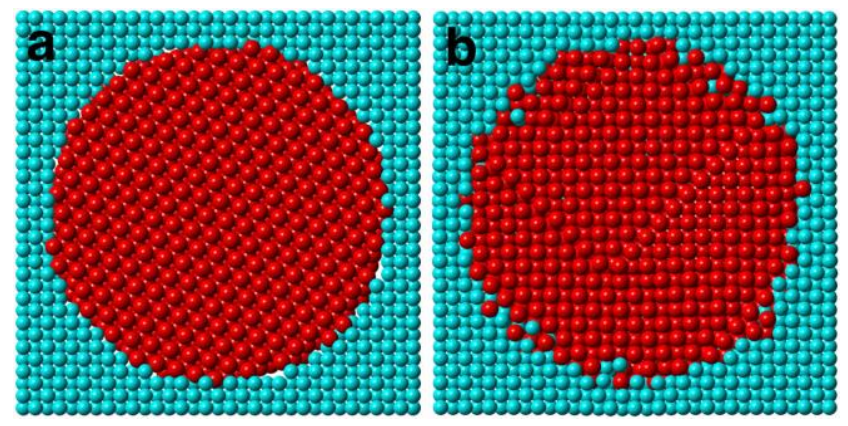

Fig. 2. Structure of an embedded $\mathrm{Ag}$ particle in a Ni matrix ( $\mathrm{Ag}$ atoms red and $\mathrm{Ni}$ atoms blue). (a) Slice along a $\mathrm{Ni}(100)$ plane through the approximate center of the initial configuration of a Ag particle in an oct-cube OR on the $\mathrm{Ni}(100)$ plane, (b) after heating to $1250 \mathrm{~K}$, cooling to $900 \mathrm{~K}$, then holding $4 \mathrm{nsec}$ at $900 \mathrm{~K}$, the particle acquires a cube-on-cube OR.

The three resulting configurations were treated by MD using the following cycle: preheating gradually to $1250 \mathrm{~K}$, cooling to $900 \mathrm{~K}$, equilibrating at $900 \mathrm{~K}$ for $4 \mathrm{nsec}$, and finally applying LS so as to remove thermal noise. Although $1250 \mathrm{~K}$ lies a few degrees above the melting point of $\mathrm{Ag}(1235 \mathrm{~K})$ it is quite common for embedded particles to remain solid well above their melting points, as has been shown experimentally for the case of Ag embedded in $\mathrm{Ni}$ [22]. No evidence of melting was detected in the present simulations. The final configuration for all three initial ORs was a cube-on-cube OR of Ag in the Ni matrix (as shown in Fig. $2 b$ for the case of the initially oct-cube OR displayed in Fig. 2a) clearly indicating that cube-on-cube was the preferred (i.e. equilibrium) OR. Since the above results established that a cube-on-cube OR is the equilibrium 3-D OR, all further results on embedded Ag particles are reported for computations using an initial cube-on-cube OR.

\section{Intermediate constraints - particles in dimples}

In order to produce particles with constraints lying between 2-D and complete confinement within a matrix (3-D), simulations were also performed on Ag particles partly embedded in dimpled $\mathrm{Ni}(100)$ substrates. The dimple depth was varied as a means of changing the degree of 3-D constraint imposed on the Ag phase. In addition, two dimple shapes were used, spherical dimples as illustrated in Fig. 3, and facetted dimples as shown in Fig. 4. 

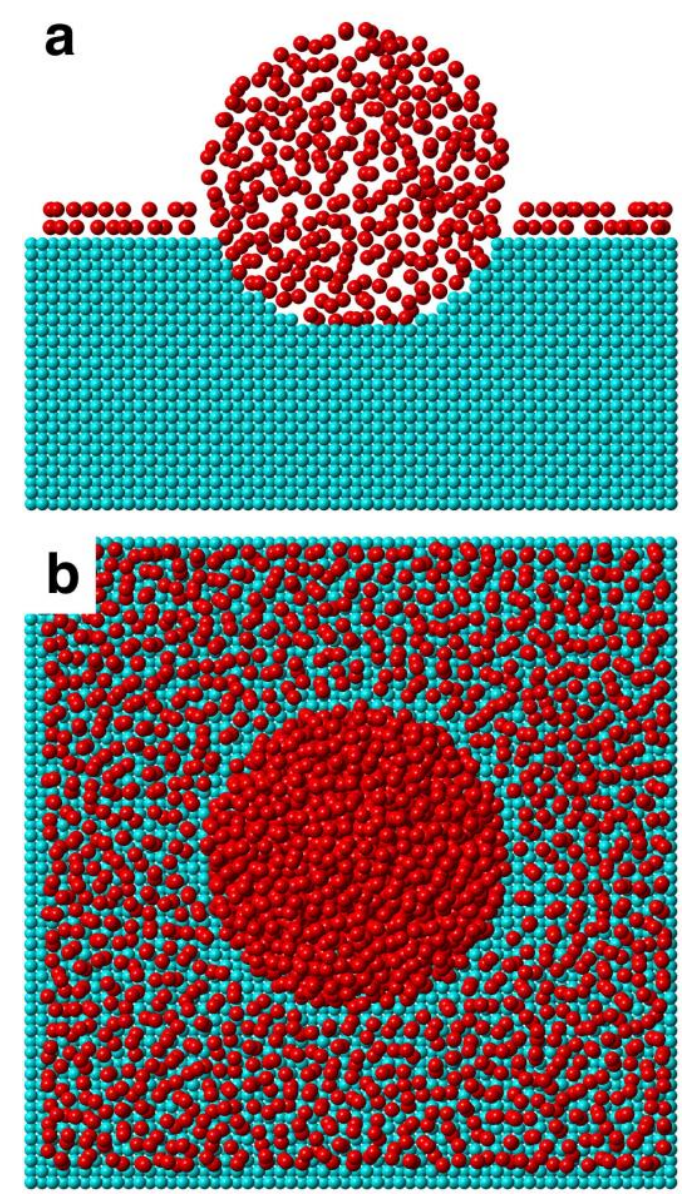

Fig. 3. Example of the initial configuration for the simulation of $\mathrm{Ag}$ on a $\mathrm{Ni}\{100\}$ substrate with a spherical dimple; Ag atoms in red, Ni atoms in blue. (a) Slice through center of substrate, (b) top view.

Fig. 3a shows a slice through the center of the initial configuration of a computational cell for the simulation of a $\mathrm{Ag}$ particle on a dimpled $\mathrm{Ni}$ substrate. The dimple in this $\mathrm{Ni}(100)$ substrate is shaped in the form of a spherical segment of radius $r=7 a_{N i}$, where $a_{N i}$ is the $\mathrm{Ni}$ lattice constant. The depth of the dimple shown in Fig. 3 is $4 \mathrm{a}_{\mathrm{Ni}}$. Ag is distributed in two ways: as a randomly arranged sphere of $\mathrm{Ag}$ atoms that sits in the dimple, and as randomly located $\mathrm{Ag}$ atoms on the planar region of the slab surface; a view of the initial configuration from above is shown in Fig. 3b. When configurations with just the random Ag sphere are used as the initial configuration (i.e. without the added $\mathrm{Ag}$ on the planar Ni surface), Ag from the sphere spreads out over the flat $\mathrm{Ni}$ surface during MD equilibration to form an adsorbed $\mathrm{Ag}$ surface layer that coexists in equilibrium with the 3-D Ag particle in the dimple. Since this diffusive process is slow, placing some Ag initially on the flat part of the Ni substrate allows a reduction of the time taken for equilibration of the Ni surface. Also, by distributing both the 
$\mathrm{Ag}$ in the dimple and on the planar $\mathrm{Ni}$ surface initially in a random manner, any bias on the structure of the $\mathrm{Ag}$ that might be inherited from the initial configuration is avoided.
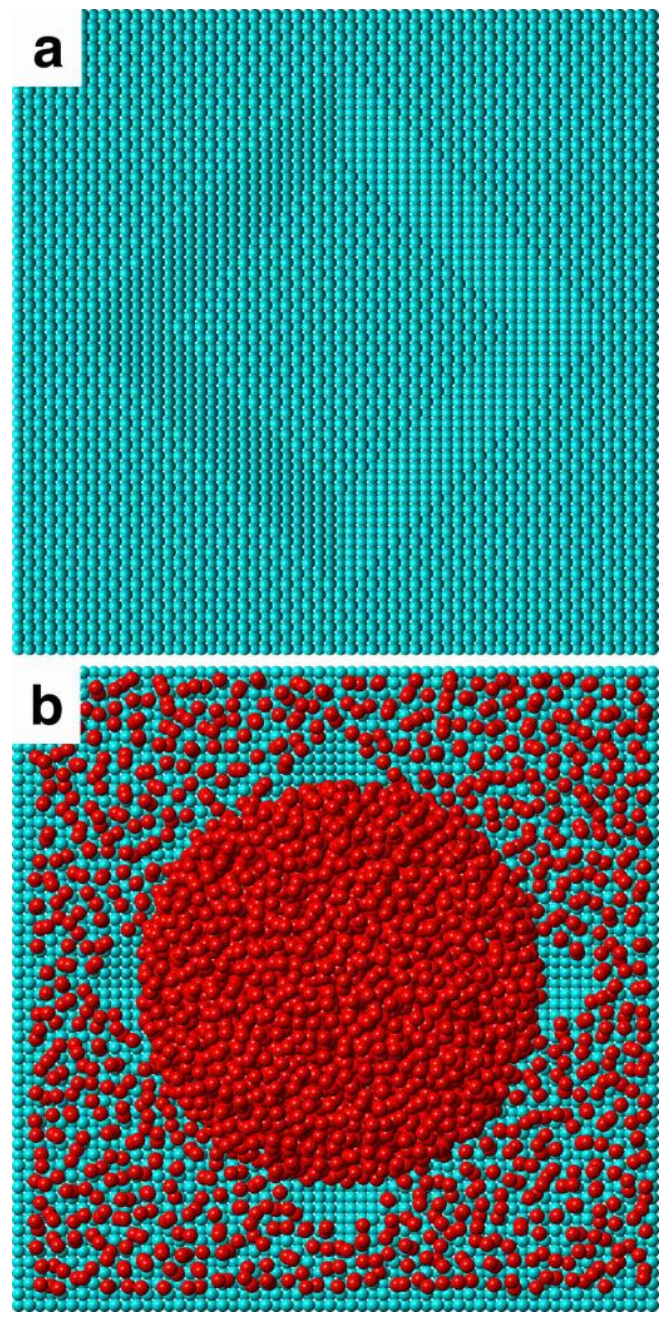

Fig. 4. (a) Example of a Ni substrate with a deep facetted dimple. (b) Initial configuration of $\mathrm{Ag}$ for the case of a facetted dimple, as viewed from above (cf. Fig. 3b).

Computations have also been performed using dimples with facetted shapes in order to assess the effects of dimple shape on progressive confinement of $\mathrm{Ag}$. The shape of the facetted dimple is shown in Fig. $4 a$. Dimple depth in Fig. $4 a$ is $4 a_{N i}$. Figure $4 b$ shows the structure of the initial Ag configuration prior to MD simulation; the Ag is randomly distributed in the form of a sphere in the region of the dimple, and as a random layer over the planar substrate, as was the case for the spherical dimple described in Fig. 3.

\section{Common neighbor analysis}

In addition to the simulations described above, some of the structures resulting from MD and/or LS were subjected to the so-called common neighbor analysis (CNA) [23]. This 
type of analysis is able to examine the environment of an atom and determine whether it occupies a site with surroundings that are characteristic of a particular crystal structure. The CNA used here was limited to identifying atoms in sites with surroundings characteristic of FCC, HCP or "unknown" types of sites.

\section{RESULTS AND DISCUSSION}

\section{3-D Ag confinement in Ni}

We begin by describing the results of simulations of $\mathrm{Ag}$ embedded in $\mathrm{Ni}$, where the primary purpose was to gain information on the OR of $\mathrm{Ag}$ for the case of complete 3-D confinement. Figure 5 displays 2 views, along a close packed $<110>$ direction, of slices through the approximate center of an equilibrated Ag particle embedded in Ni. Figure $5 \mathrm{a}$ shows the Ag particle together with the surrounding $\mathrm{Ni}$, whereas Fig. $5 \mathrm{~b}$ is a view of just the Ag particle, with a color-coding corresponding to a determination of site coordination by CNA. "Unknown" sites in Fig. 5b (colored green) are either sites located on the interface of the particle, which lack a full complement of Ag neighbors and are therefore unidentifiable, or ones located in regions where the local crystalline order has been disturbed by defects of various types.

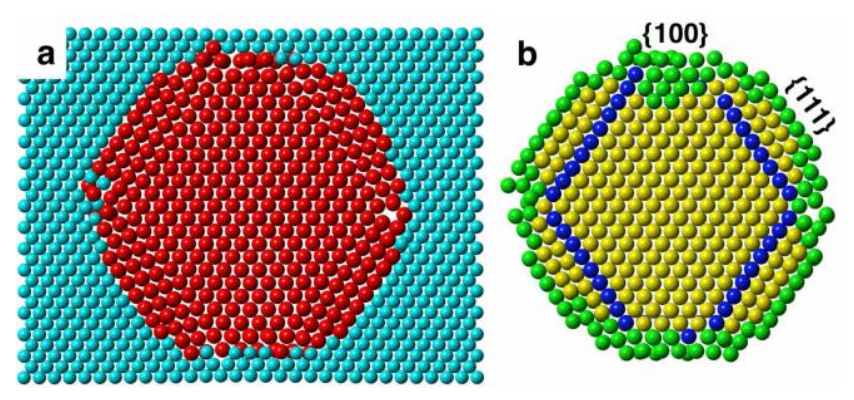

Fig. 5. Slices of an embedded Ag particle after equilibration for $4 \mathrm{nsec}$ at $900 \mathrm{~K}$, viewed along a $<110>$ direction. (a) Slice through the approximate center of the Ag particle and the surrounding Ni matrix (Ag atoms red, and Ni atoms light blue); (b) slice through the Ag particle after applying the common neighbor analysis (atoms in FCC sites yellow, those in HCP sites dark blue, and unknown sites green).

Several features are worthy of note. The Ag particle is bounded primarily by $\{100\}$ interface planes (top and bottom) and by $\{111\}$ interface planes (diagonal planes on left and right hand sides of the figure). There may be small $\{110\}$ interface planes at the junction between the two $\{111\}$ interface planes on the left and right edges respectively; however these regions appear to be rounded rather than flat, implying that, at the equilibration temperature of $900 \mathrm{~K}$, the $\{110\}$ interfaces lie above their roughening temperature. Whereas 
the core of the Ag particle is clearly aligned with the surrounding Ni crystal (Fig. 5a), indicating a cube-on-cube $\mathrm{OR}$, the regions near the $\{111\}$ faces display different orientations. In particular, in Fig. $5 b$, the regions near the $\{111\}$ faces are seen to be separated from the cube-on-cube core by single $\{111\}$ planes that display a hexagonal CNA assignment. Such single hexagonally coordinated planes in FCC crystals represent coherent twin grain boundaries.

Finally, it is important to mention that the cube-on-cube OR found by MD is consistent with the OR found experimentally by electron diffraction in TEM, for Ag particles embedded in $\mathrm{Ni}$, prepared by melt spinning of $\mathrm{Ni}-10 \% \mathrm{Ag}$ ribbons [22]. Such a cube-on-cube OR has also been observed experimentally for $\mathrm{Pb}$ particles equilibrated in $\mathrm{Al}$, a similar low mutual solubility binary system [24] with large lattice mismatch.

\section{2-D Ag confinement on Ni substrates}

In the previous work mentioned above [1], the behavior of Ag films equilibrated on a large number of Ni substrates of different orientations has been studied. That work showed that the range of observed ORs was quite large, as there is a whole family of "special" ORs which represent a gradual transition from the oct-cube OR on Ni\{100\} to the twin/cube-oncube ORs displayed along the dashed line labeled T/C-C in Fig. 1. Those results were summarized above in Fig. 1. However, when completely embedded in $\mathrm{Ni}, \mathrm{Ag}$ displays a single $\mathrm{OR}$, the cube-on-cube $\mathrm{OR}$, as has been demonstrated in the previous section. This 3-D OR is consistent with the OR observed on Ni substrates with orientations lying in the (111)-(110)(210) orange region of Fig. 1, but coincides neither with the 2-D oct-cube OR of Ag on $\mathrm{Ni}(100)$, nor with the family of special ORs. Thus, one important question still needs to be answered: as a Ag crystal is gradually embedded in, say, $\mathrm{Ni}(100)$, at what point does it undergo a change from 2-D to 3-D behavior?

\section{Gradual increase in $\mathrm{Ag}$ confinement in $\mathrm{Ni}$}

A gradual change in $\mathrm{Ag}$ confinement was accomplished by simulations of $\mathrm{Ag}$ on dimpled $\mathrm{Ni}\{100\}$ substrates. Dimples were either in the shape of a spherical segment, or fully facetted with a $\{100\}$ bottom and $\{111\}$ sides, so as to mimic part of the shape of a fully embedded particle such as the example shown in Fig. 5. Dimple depth was gradually increased in order to modify the extent of confinement. 

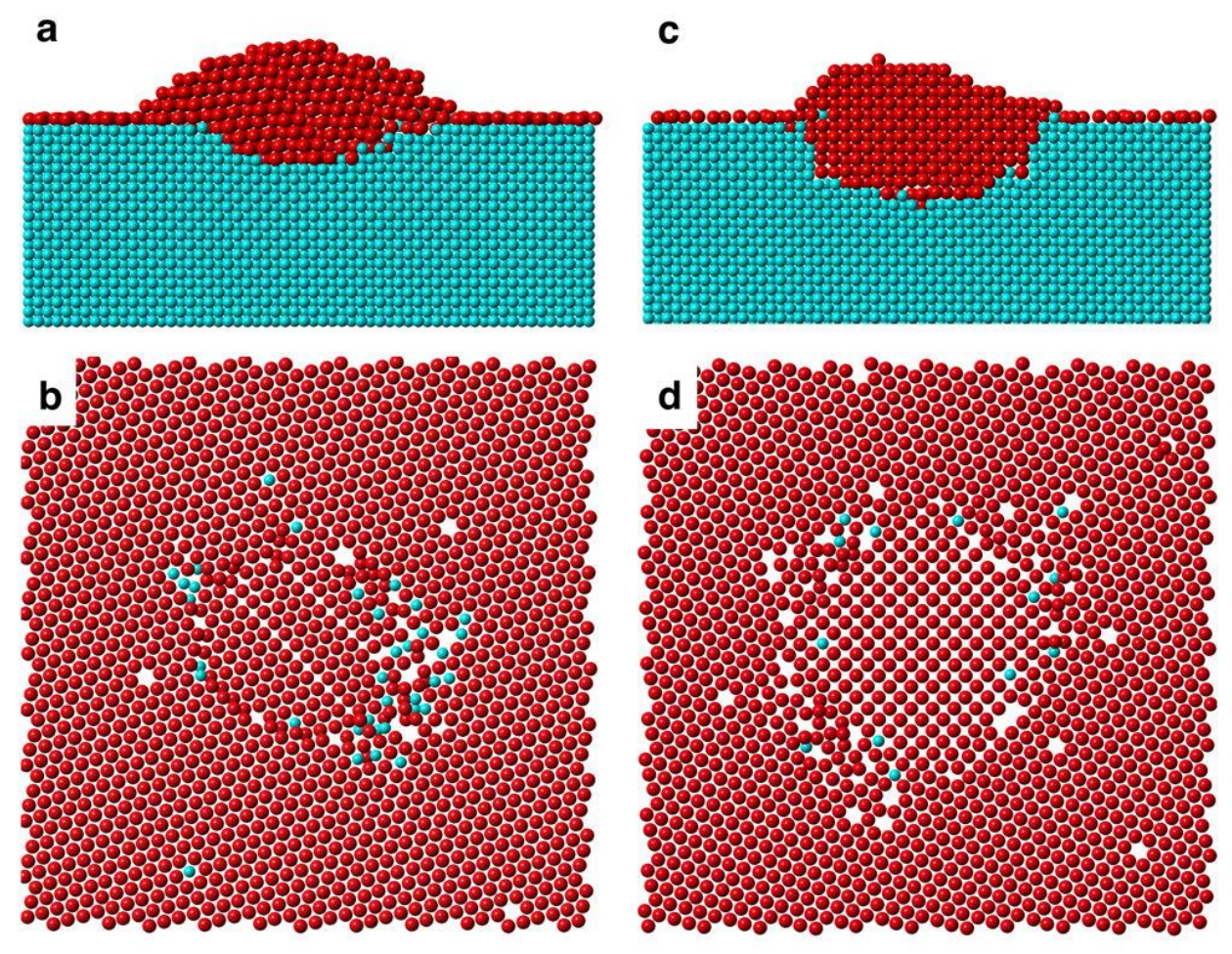

Fig. 6. Ag particle on dimpled $\mathrm{Ni}\{100\}$ substrates, after MD equilibration (Ag atoms in red, $\mathrm{Ni}$ atoms in blue). Dimple depth was varied from 2 Ni-lattice constants in (a) and (b), to $4 \mathrm{Ni}$ lattice constants in (c) and (d). (a) and (c) are vertical slices through the center of the dimple, and (b) and (d) are horizontal slices at the level of the Ag adsorption layer on the planar surface of the Ni substrates.

We first describe the results of equilibrating $\mathrm{Ag}$ on $\mathrm{Ni}\{100\}$ substrates with dimples in the shape of spherical segments. These dimples were all $7 \mathrm{Ni}$ lattice constants in radius, but varied in depth. Examples of dimples with depths of 2 and $4 \mathrm{Ni}$ lattice constants are shown in Fig. 6. These results were obtained by MD simulations at $900 \mathrm{~K}$ of initial configurations similar to those shown earlier in Fig. 2. In the case of the shallow dimple, the structure of Ag can be seen in Fig. $6 \mathrm{a}$ to consist of a Ag particle in the dimple and a Ag adsorbed monolayer over the planar part of the substrate. In Fig. 6b, which is a slice at the level of the Ag adsorbed monolayer, both the adsorbed $\mathrm{Ag}$ as well as the $\mathrm{Ag}$ in the dimple can be seen to have a hexagonal symmetry on the $\mathrm{Ni}\{100\}$ substrate (with the exception of an occasional fault) as expected for an oct-cube OR. In contrast, in Fig. $6 \mathrm{~d}$ for the case of the deeper dimple, there is a clear difference in structure between the hexagonal adsorbed $\mathrm{Ag}$ monolayer and the portion of the Ag slice through the Ag particle in the dimple, which displays a square symmetry consistent with a cube-on-cube OR for the portion of $\mathrm{Ag}$ in the dimple. Thus, the OR of the partially constrained particle undergoes a transition from oct-cube when equilibrated in a shallow dimple to a cube-on-cube OR when equilibrated in a deeper dimple. This transition takes place for a dimple depth lying between 2 and 4 Ni lattice constants. 
Since the oct-cube $\mathrm{OR}$ is strongly dependent on Ag equilibration with $\mathrm{Ni}\{100\}$ surfaces it was considered important to determine whether simulations performed on fully facetted dimples, with well-defined $\{100\}$ planes, would also show the transition from oct-cube to cube-on-cube at a dimple depth similar to the case of spherically-shaped dimples. Results of those simulations are summarized in Fig. 7.

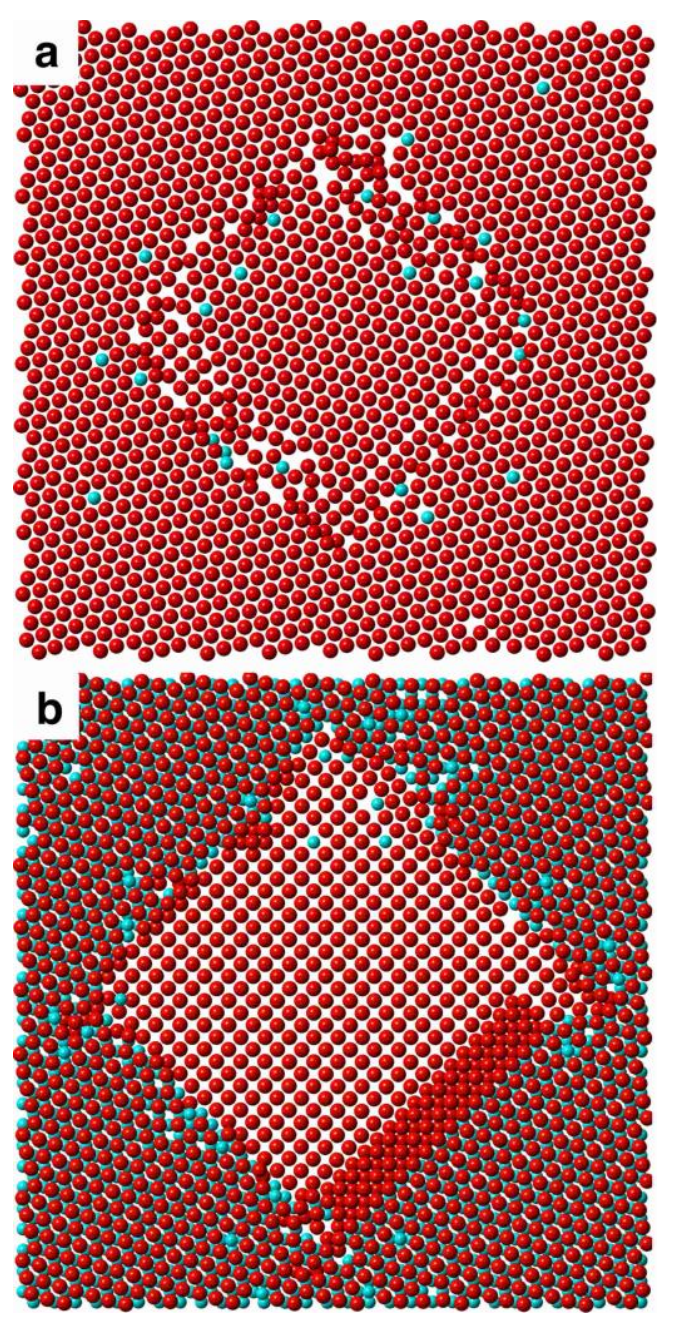

Fig. 7. Horizontal slices at the level of the adsorbed Ag monolayer on a planar Ni $\{100\}$ surface after MD equilibration at $900 \mathrm{~K}$. (a) Ag equilibrated on substrate with a dimple depth of $2 \mathrm{Ni}$ lattice constants, and (b) Ag equilibrated on a substrate with a dimple depth of 4 Ni-lattice constants. (Ag atoms in red, $\mathrm{Ni}$ atoms in blue).

The shapes of a facetted dimple, and of the initial Ag configuration in such a dimple were shown earlier in Fig. 4. The results of MD simulation on a substrate with a dimple having a bottom $\{100\}$ facet of about $12 \mathrm{Ni}$ lattice constants on a side and a depth of 2 Ni-lattice constants are shown in Fig. 7a. The figure shows a slice through the dimple at the level of the adsorbed Ag monolayer on the planar part of the Ni substrate. The Ag displays a hexagonal 
symmetry in both the adsorbed layer and in the portion of the Ag particle residing in the dimple, as is consistent with an oct-cube OR. Figure 7b shows that for a substrate with a dimple of $4 \mathrm{Ni}$-lattice constants in depth (and the same size bottom facet) the Ag over the dimple has adopted a square symmetry characteristic of a cube-on-cube OR. These results are essentially the same as those obtained on substrates with spherical dimples, and confirm that a transition in OR from oct-cube to cube-on-cube occurs for dimple depths of between 2 and $4 \mathrm{Ni}$ lattice constants. However, it should be emphasized that the depth of the dimple at the transition from oct-cube to cube-on-cube OR depends on the ratio of the area of the bottom $\{100\}$ facet to that of the lateral $\{111\}$ facets, as discussed in more detail in the appendix.

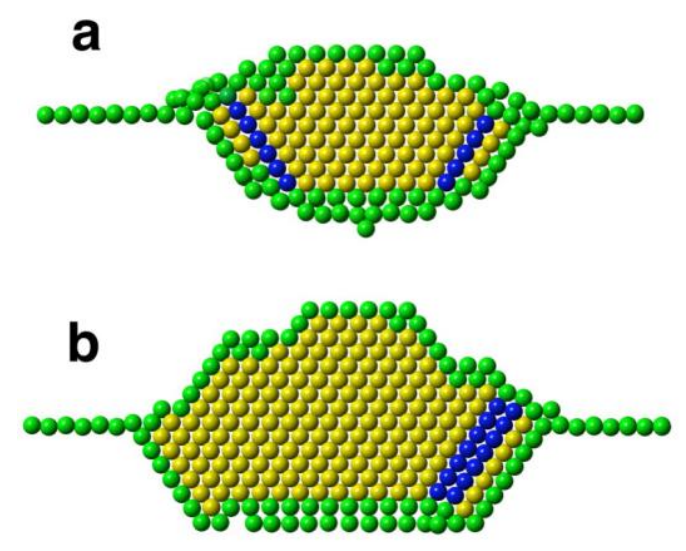

Fig. 8. Results of CNA on slices through Ag particles viewed along a $<110>$ direction, with atoms in FCC sites colored yellow, those in HCP sites in dark blue, and sites with unknown coordination in green. (a) Particle in a $4 a_{N i}$ deep dimple in the shape of a spherical segment, (b) particle in a $4 \mathrm{a}_{\mathrm{Ni}}$ deep facetted dimple.

It is also interesting to investigate the defects that are present in partially embedded $\mathrm{Ag}$, as determined by CNA, after simulation by MD. Figure 8 shows the results of CNA performed on $\mathrm{Ag}$ residing on $\mathrm{Ni}\{001\}$ substrates with dimples either in the shape of spherical segments (Fig. 8a) or entirely facetted (Fig. 8b). The particle in Fig. 8a displays one layer of atoms with hexagonal coordination (colored blue) in the vicinity of both of its visible $\{111\}$ edges, much like the completely embedded Ag particle of Fig. 5b. As mentioned earlier, a single $\{111\}$ plane of atoms with hexagonal coordination is the signature of a coherent twin grain boundary. The Ag particle in the facetted dimple (Fig. 8b) displays two adjacent $\{111\}$ planes with hexagonal coordination in the vicinity of only one of its visible $\{111\}$ edges. The double $\{111\}$ hexagonal layer is the signature of an intrinsic stacking fault. The CNA results 
shown here are, however, not unique, in the sense that different computations performed from the same starting configuration, but using different seeds for the random number generator used in the simulations, could produce different defect structures. However, coherent twin grain boundaries were the most common type of planar defects observed to occur near the $\{111\}$ interfaces of $\mathrm{Ag}$ particles during these simulations.

\section{CONCLUSIONS}

Comparison of the results of simulations in which $\mathrm{Ag}$ was equilibrated on 2-D $\mathrm{Ni}$ substrates with those of simulations in which Ag was embedded in Ni (3-D confinement) showed the following differences. Whereas equilibration of $\mathrm{Ag}$ embedded in Ni produces a single equilibrium $\mathrm{OR}$, specifically a cube-on-cube $\mathrm{OR}$, equilibration of $\mathrm{Ag}$ on flat Ni substrates (i.e. 2-D confinement) produces a series of ORs, as was shown in our previous experiments [1]. This is an important observation, as it runs contrary to conventional wisdom, which supposes that the ORs displayed in the presence of 3-D confinement (e.g. during phase transformations) will also tend to be displayed in epitaxy on a substrate. Thus, one important conclusion from this work is that ORs produced by 3-D confinement do not provide an appropriate basis for inferring the ORs that arise when films are deposited and equilibrated on planar substrates.

It has also been shown that by progressively increasing the degree of 3-D confinement of $\mathrm{Ag}$ particles, through an increase in the depth of dimples at the surface of $\mathrm{Ni}\{100\}$ substrates, it is possible to produce a transition from an oct-cube OR for Ag equilibrated in shallower dimples, to a cube-on-cube $\mathrm{OR}$ for $\mathrm{Ag}$ in deeper dimples. The specific details of the depth at which the transition occurs are sensitive to the interfacial energies of the dimple.

\section{Acknowledgments}

PW wishes to acknowledge use of the computational resources of the National Energy Research Scientific Computing Center, which is supported by the Office of Science of the U.S. Department of Energy under Contract No. DE-AC02-05CH11231. DC wishes to thank the Agence Nationale de la Recherche for support of her research under grant ANR-GIBBS-15CE30-0016. In addition, the authors wish to thank Prof. N. Bozzolo for useful discussions.

\section{Conflicts of Interest}

The authors declare that they have no conflicts of interest.

\section{$\underline{\text { References }}$}


[1] Chatain D, Wynblatt P, Rollett AD, Rohrer GS (2015) Importance of interfacial step alignment in hetero-epitaxy and orientation relationships: the case of $\mathrm{Ag}$ equilibrated on $\mathrm{Ni}$ substrates. Part 2 experiments. J Mater. Sci. 50:5276-5285.

[2] Wynblatt P, Chatain D (2015) Importance of interfacial step alignment in hetero-epitaxy and orientation relationships: the case of Ag equilibrated on Ni substrates. Part 1 computer simulations. J Mater. Sci. 50:5262-5275.

[3] Plimpton S] (1995) Fast parallel algorithms for short-range molecular dynamics, J Comp Phys 117:1-19.

[4] http://www.cs.sandia.gov/ sjplimp/lammps.html Accessed 2 May 2015

[5] Foiles SM, Baskes MI, Daw MS (1986) Embedded-atom-method functions for the fcc metals $\mathrm{Cu}, \mathrm{Ag}, \mathrm{Au}, \mathrm{Ni}, \mathrm{Pd}, \mathrm{Pt}$, and their alloys, Phys Rev B 33:7983.

[6] Dregia SA, Bauer CL, Wynblatt P (1986) The structure and composition of interphase boundaries in Ni/Ag-(001) thin films doped with Au, Mater Res Soc Symp Proc 56:189-194.

[7] Dregia SA, Wynblatt P, Bauer CL (1987) Epitaxy for weakly interacting systems of large misfit, Mater Res Soc Symp Proc 94:111-120.

[8] Dregia SA, Wynblatt P, Bauer CL (1989) Computer simulations of epitaxial interfaces, Mater Res Soc Symp Proc 141:399-404.

[9] Gao Y, Dregia SA, Shewmon PG (1989) Energy and structure of (001) twist interphase boundaries in the Ag/Ni system, Acta Metall 37:1627-1636.

[10] Gao Y, Shewmon PG, Dregia SA (1989) Investigation of low-energy interphase boundaries in Ag/Ni by computer simulation and crystallite rotation, Acta Metall 37:3165-3175. [11] Maurer R, Fischmeister HF (1989) Low energy heterophase boundaries in the system silver/nickel and in other weakly bonded systems, Acta Metall 37:1177-1189.

[12] Gao Y, Merkle KL (1990) Atomic Structure of Ag/Ni interfaces, Mater Res Soc Symp Proc 183:39-44.

[13] Gao Y, Merkle KL (1990) High-resolution electron microscopy of metal/metal and metal/metal-oxide interfaces in the Ag/Ni and Au/Ni systems, J Mater Res 5:1995-2003.

[14] Gumbsch P, Daw MS, Foiles SM, Fischmeister HF (1991) Accommodation of the lattice mismatch in a Ag/Ni heterophase boundary, Phys Rev B 43:13833.

[15] Gumbsch P (1992) Atomistic study of misfit accommodation in cube-on-cube oriented $\mathrm{Ag} / \mathrm{Ni}$ heterophase boundaries, Z Metallkd 83:500-507.

[16] Allameh SM, Dregia SA, Shewmon PG (1994) Structure and energy of (110) twist boundaries in the Ag/Ni system, Acta Metall Mater 42:3569-3576.

[17] Allameh SM, Dregia SA, Shewmon PG (1996) Energy of (110) twist boundaries in Ag/Ni and its variation with induced strain, Acta Mater 44:2309-2316. 
[18] Floro JA, Thompson CV, Carel R, Bristowe PD (1994) Competition between strain and interface energy during epitaxial grain growth in $\mathrm{Ag}$ films on $\mathrm{Ni}(001), \mathrm{J}$ Mater Res 9:24112424.

[19] Gumbsch P (1997) The accommodation of lattice mismatch in $\mathrm{Ag} / \mathrm{Ni}$ heterophase boundaries, J Phase Equilibria 18:556-561.

[20] Mroz S, Jankowski Z, Nowicki M (2000) Growth and isothermal desorption of ultrathin silver layers on the $\mathrm{Ni}(111)$ face at the substrate temperature from 180 to $900 \mathrm{~K}$, Surface Sci 454:702-706.

[21] Chambon C, Creuze J, Coati A, Sauvage-Simkin M, Garreau Y (2009) Tilted and nontilted Ag overlayer on a Ni(111) substrate: structure and energetics, Phys Rev B 79:125412, and references therein.

[22] Zhong J, Zhang LH, Jin ZH, Sui ML, Lu K (2001) Superheating of Ag nanoparticles embedded in Ni matrix, Acta Mater 49:2897-2904.

[23] Faken D, Jonsson H (1994) Systematic analysis of local atomic structure combined with 3D computer graphics, Computational Materials Science 2:279-286.

[24] Dahmen U, Xiao SQ, Paciornik S, Johnson E, Johansen A (1997) Magic-Size Equilibrium Shapes of Nanoscale Pb Inclusions in Al, Phys Rev Lett 78:471-474, and refs therein. 


\section{Appendix}

As a first approximation, we take the total excess energy of a Ag particle in a facetted dimple substrate to be the sum of the energies of all its interfaces multiplied by their areas. For the purpose of these estimates we shall use the energies of the Ni/Ag interfaces computed by Gao et al. [10], using the same EAM potentials as those used in the present MD simulations. Those are listed in Table 1.

Table 1. Calculated Ni/Ag interfacial energies $\left(\mathrm{mJ} / \mathrm{m}^{2}\right)$ [10]

\begin{tabular}{|c|c|c|c|}
\hline & $\operatorname{Ag}\{100\}$ & $\operatorname{Ag}\{110\}$ & $\operatorname{Ag}\{111\}$ \\
\hline $\mathrm{Ni}\{100\}$ & 814 & 1124 & 437 \\
\hline $\mathrm{Ni}\{110\}$ & 995 & 828 & 988 \\
\hline $\mathrm{Ni}\{111\}$ & 670 & 960 & 416 \\
\hline
\end{tabular}

Let us begin by comparing the energies of the bottom $\mathrm{Ni}\{100\}$ dimple interface for the cases of an oct-cube vs. a cube-on-cube OR. The energy of the oct-cube $\mathrm{Ni}\{100\} / \mathrm{Ag}\{111\}$ interface is $437 \mathrm{~mJ} / \mathrm{m}^{2}$, and for the cube-on-cube $\mathrm{Ni}\{100\} / \mathrm{Ag}\{100\}$ it is $814 \mathrm{~mJ} / \mathrm{m}^{2}$. Thus, the dimple bottom interface has a clear energy advantage in the oct-cube vs. the cube-on-cube comparison. As the depth of the dimple increases, a progressively larger fraction of the interface will consist of $\mathrm{Ni}\{111\}$ facets. In the case of the cube-on-cube OR the resulting four $\mathrm{Ni}\{111\} / \mathrm{Ag}\{111\}$ interfaces have the lowest energy, namely: $416 \mathrm{~mJ} / \mathrm{m}^{2}$. This is consistent with the expectation that $\{111\} /\{111\}$ interfaces in FCC metals will tend to have the lowest interfacial energy.

In the case of the oct-cube $\mathrm{OR}$, the $\mathrm{Ag}$ side of the four $\mathrm{Ni}\{111\}$ interfaces are all different: they consist of $\mathrm{Ag}\{100\}$ and $\{221\}$ planes as well as two other high index planes. Of these interfaces, only the energy of the $\mathrm{Ni}\{111\} / \mathrm{Ag}\{100\}$ is known to be $670 \mathrm{~mJ} / \mathrm{m}^{2}$. The average of all the interfacial energies computed by Gao et al. [10] is about $800 \mathrm{~mJ} / \mathrm{m}^{2}$. Considering this figure to be a reasonable estimate of the average energy of the $\mathrm{Ni}\{111\} / \mathrm{Ag}\{\mathrm{hkl}\}$ interfaces, it is clear that a transition in stability from oct-cube to cube-oncube OR will occur when the area of $\mathrm{Ni}\{111\}$ will exceed $\mathrm{Ni}\{100\}$ area at the $\mathrm{Ni} / \mathrm{Ag}$ interface, i.e. somewhere between a dimple depth of $2 \mathrm{a}_{\mathrm{Ni}}$ and $4 \mathrm{a}_{\mathrm{Ni}}$.

It is worth noting that the contribution of strain energy to the total excess energies of the two configurations may also contribute to the transition. 